\title{
SPINAL FUSION WITH FREE PERIOSTEAL GRAFTS AND ITS EFFECT ON VERTEBRAL GROWTH IN YOUNG RABBITS
}

\author{
V. Ritsilä and S. Alhopuro, Helsinki, Finland \\ From the Research Laboratory of the Orthopaedic Hospital of the Invalid Foundation, Helsinki
}

\begin{abstract}
The effect of early fusion on growth of the spine has been studied in rabbits. Free periosteal grafts from the tibia were transplanted either posteriorly between the spinous and articular processes or postero-laterally between the articular and transverse processes. Sound bony fusion was achieved in both the thoracic and the lumbar spine. Spinal fusion caused local narrowing and wedging of the intervertebral spaces, followed by retardation of growth and wedging of the vertebrae. A progressive structural scoliosis developed after unilateral postero-lateral fusion and a lordosis developed after posterior fusion.
\end{abstract}

Experimental attempts to produce sound fusion of the growing spine have generally been unsuccessful and have therefore failed to throw much light on the clinical problem. Successful fusion has been achieved in dogs by Albee (1913), Haas (1940), Hurley, Stinchfield, Basset and Lyon (1959), Veliskakis and Levine (1966) and Coleman (1968), and in goats by Bisgard and Musselman (1940). In rabbits spinal fusion has been attempted, but not achieved, by Kornew (1929), Odelberg-Johnson (1939), Risser (1956) and Johnson and Southwick (1960a). Continued growth in the length of the spine of a young animal routinely occurs after attempted fusion when pseudarthroses develop at the interspaces.

In our earlier studies we achieved the rapid formation of strong bone with free periosteal grafts both in rabbits (Ritsilä, Alhopuro and Rintala 1972; Ritsilä and Alhopuro 1972, 1973) and in children (Ritsilä, Alhopuro, Gylling and Rintila 1972). In the present study periosteum from the tibia was transplanted to different parts of the thoracic and lumbar spine of growing rabbits; bony fusion was achieved in a high percentage and its properties were assessed.

\section{MATERIAL AND METHOD OF STUDY}

The experimental material comprised fifty-eight rabbits aged from four to seventy-seven days at the time of operation. Of these, twenty-two were used for special purposes. Thus ten rabbits were killed at intervals of two days after periosteal grafting in order to determine histologically the early behaviour of the transplant and the development of a fusion mass. Twelve more were subjected to a mock operation omitting the transplant, four each on the thoracic, thoraco-lumbar and lumbar spines; in no case did this lead to fusion, curvature or disturbance of growth. The actual results of periosteal grafting are therefore based on the findings in thirty-six rabbits.

These animals were anaesthetised with intravenous Nembutal 30 milligrams/kilogram of body weight or by local injection of Xylocaine. The periosteum was stripped from the anterior aspect of the left tibia with the aid of a scalpel, transplants as large as possible being raised. Usually a small amount of the tibialis cranialis muscle, which corresponds to the tibialis anticus in humans, was present in the graft, as it was almost impossible to keep it from breaking if all the muscle were cleaned off. The transplants shrank about one-third after being raised.

The periosteum was placed either posteriorly between the spinous and articular processes, on one or both sides, or postero-laterally between the articular and transverse processes, on one side only. The bony bed having been exposed subperiosteally, each transplant was laid with its original deep aspect next the bone. In six rabbits, bilateral posterior grafting was performed; in the remaining thirty the grafting was performed on one side only. In some experiments two strips were used to induce a long fusion mass.

The transplants extended over two to five vertebrae at different levels between the eighth thoracic and the seventh lumbar vertebrae.* In sixteen rabbits the thoracic, in seven the thoraco-lumbar, and in thirteen the lumbar region was prepared for transplantation. In most experiments the transplants were fixed with catgut, in some they were left loose under the muscle, and in seven animals, early in the series, a tissue adhesive (Histoacryl) was used. No external immobilisation was used nor was the activity of the rabbits restricted in any way.

Antero-posterior and lateral radiographs were taken immediately after operation, at intervals of one, three and five weeks, two and three months, and thereafter at monthly intervals until the rabbit was either killed or died from natural causes. The longest follow-up was $\mathbf{4 8 0}$ days.

Post-mortem studies consisted of radiographs, macroscopic examination and histology. Besides antero-posterior and lateral films, radiographs were taken with the spine flexed in order to determine its stability and to reveal any pseudarthroses. In the macroscopic examination the state of union at each level was tested by attempts to elicit movement. In many experiments the bone specimen was dissected free and photographed. For histology the fused segment was fixed, decalcified, embedded in paraffin, sectioned, and stained with haematoxylin and eosin. About twenty sagittal sections were made from each specimen.

* Note that the rabbit has thirteen thoracic and seven lumbar vertebrae.

Veijo Ritsilä, M.D., Research Laboratory of the Orthopaedic Hospital of the Invalid Foundation, Tenholantie 10, SF-00280 Helsinki 28, Finland.

S. Alhopuro, M.D., Research Laboratory of the Orthopaedic Hospital of the Invalid Foundation, Tenholantie 10, SF-00280 Helsinki 28, Finland. 
TABLE I

The Results of Attempted Spinal Fusion with Free Periosteal Grafts in Thirty-six Young Rabbits

\begin{tabular}{|c|c|c|c|c|c|c|c|c|c|c|c|c|}
\hline 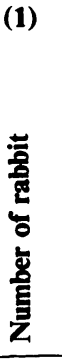 & 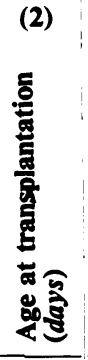 & 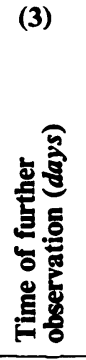 & 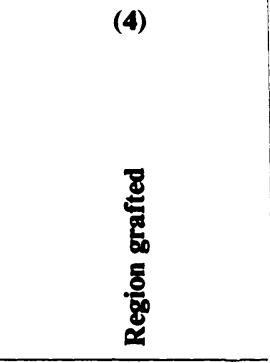 & 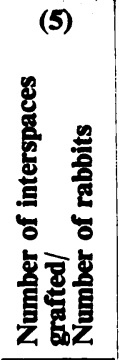 & 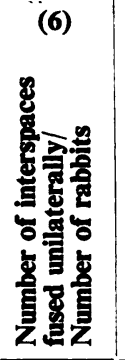 & 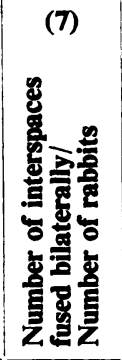 & 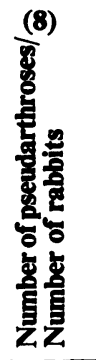 & 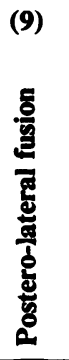 & 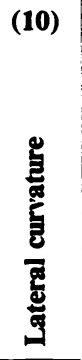 & 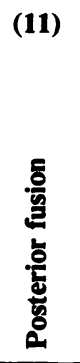 & $\begin{array}{l}\frac{n}{5} \\
\frac{8}{5}\end{array}$ & 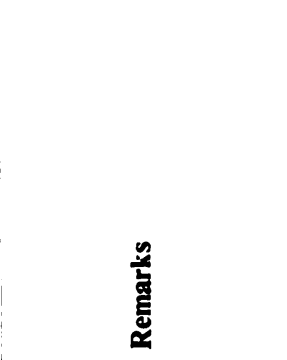 \\
\hline 1 & 69 & 285 & T.10-11 & 1 & 0 & & 1 & & & & & Tissue adhesive \\
\hline 2 & 69 & 285 & T.10-11 & 1 & $\mathbf{0}$ & & 1 & & & & & Tissue adhesive \\
\hline 3 & 69 & 194 & T.10-11 & 1 & $\mathbf{0}$ & & 1 & & & & & Tissue adhesive \\
\hline 4 & 69 & 285 & T.10-11 & 1 & 1 & & $\mathbf{0}$ & & & + & + & Tissue adhesive \\
\hline 5 & 69 & 285 & T.10-11 & 1 & 1 & & $\mathbf{0}$ & & & + & + & Tissue adhesive \\
\hline 6 & 77 & 228 & T.10-11 & 1 & 0 & & 1 & & & & & Tissue adhesive \\
\hline 7 & 77 & 228 & T.12-13 & 1 & 1 & & 0 & & & + & + & \\
\hline 8 & 6 & 360 & T.10-11 & 1 & 1 & & 0 & + & + & & & \\
\hline 9 & 6 & 360 & T.11-12 & 1 & 1 & & 0 & + & + & & & \\
\hline 10 & 18 & 63 & T.8-9-10 & 2 & 2 & & $\mathbf{0}$ & + & + & & & \\
\hline 11 & 20 & 480 & T.10-11-12 & 2 & 2 & & $\mathbf{0}$ & + & + & & + & \\
\hline 12 & 18 & 161 & T.11-12-13 & 2 & & 2 & 0 & & & + & + & $\begin{array}{l}\text { Tissue adhesive. See } \\
\text { Figure } 4\end{array}$ \\
\hline 13 & 20 & 311 & T.11-12-13 & 2 & 1 & & 1 & & & + & & Homograft \\
\hline 14 & 21 & 64 & T.10-11-12-13 & 3 & 2 & & 1 & + & + & & & 2 Transplants \\
\hline 15 & 21 & 262 & T.10-11-12-13 & 3 & 1 & & 2 & + & + & & + & 2 Transplants \\
\hline 16 & 20 & 195 & T.10-11-12-13 & 3 & 3 & & 0 & + & + & & + & See Figure 6 \\
\hline 17 & 6 & 163 & T.13-L.1 & 1 & $\mathbf{0}$ & & 1 & & & & & Muscle interposition \\
\hline 18 & 77 & 249 & T.13-L.1 & 1 & 1 & & $\mathbf{0}$ & & & + & + & \\
\hline 19 & 6 & 93 & T.12-13-L.1 & 2 & 2 & & 0 & + & + & & & See Figure 3 \\
\hline 20 & 18 & 63 & T.12-13-L.1 & 2 & & 2 & $\mathbf{0}$ & & & + & + & \\
\hline 21 & 24 & 62 & T.12-13-L.1 & 2 & 2 & & $\mathbf{0}$ & + & + & & & \\
\hline 22 & 24 & 390 & T.12-13-L.1-2 & 3 & 3 & & 0 & + & + & & & \\
\hline 23 & 24 & 74 & T.10-11-12-13-L.1 & 4 & 3 & & 1 & + & + & & & 2 Transplants \\
\hline 24 & 56 & 362 & L. 3-4 & 1 & 1 & & $\mathbf{0}$ & + & + & & & \\
\hline 25 & 56 & 96 & L.2-3 & 1 & 1 & & 0 & + & + & & & \\
\hline 26 & 56 & 362 & L.3-4 & 1 & 1 & & $\mathbf{0}$ & + & + & & & \\
\hline 27 & 56 & 362 & L.4-5 & 1 & & 1 & 0 & & & + & t. & \\
\hline 28 & 56 & 362 & L.4-5 & 1 & & 1 & $\mathbf{0}$ & & & + & + & \\
\hline 29 & 56 & 180 & L.4-5 & 1 & & 1 & $\mathbf{0}$ & & & + & + & \\
\hline 30 & 4 & 162 & L.6-7 & 1 & 1 & & $\mathbf{0}$ & + & + & & & \\
\hline 31 & 4 & 110 & L. 3-4 & 1 & 1 & & $\mathbf{0}$ & + & + & & & See Figure 5 \\
\hline 32 & 4 & 128 & L.1-2 & 1 & 1 & & 0 & + & + & & & \\
\hline 33 & 9 & 90 & L. 3-4 & 1 & 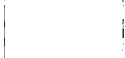 & 1 & $\mathbf{0}$ & & & + & t & \\
\hline 34 & 9 & 124 & L.6-7 & 1 & 1 & & $\mathbf{0}$ & & & + & + & \\
\hline 35 & 24 & 390 & L.4-5-6 & 2 & 2 & & $\mathbf{0}$ & + & + & & + & See Figure 1 \\
\hline 36 & 24 & 262 & L.4-5-6-7 & 3 & 3 & & 0 & + & + & & + & See Figure 2 \\
\hline & & & Totals & $57 / 36$ & $39 / 30$ & $8 / 6$ & $10 / 9$ & 19 & 19 & 12 & 16 & \\
\hline
\end{tabular}




\section{RESULTS}

The results have been set out in Table I. In the thirty-six experiments the number of interspaces grafted was fiftyseven-thirty-three thoracic, seven thoraco-lumbar and seventeen lumbar (see columns 4 and 5). The grafting was unilateral for forty-nine spaces, and bilateral, and always posterior, for the other eight spaces.

Of the forty-nine spaces grafted unilaterally, fusion occurred in thirty-nine - twenty-one thoracic, five thoracolumbar and thirteen lumbar (see column 6).
In five rabbits with postero-lateral grafts both lateral curvature and lordosis developed (see columns 10 and 12). In each of these experiments more than one interspace fused and the follow-up was longer.

\section{Radiological observations}

The first radiographic signs of new bone formation appeared during the second or third week. Gradually the ossification became more visible and after three weeks the findings began to reveal organised bone structure. Often, however, the fusion did not seem solid at this
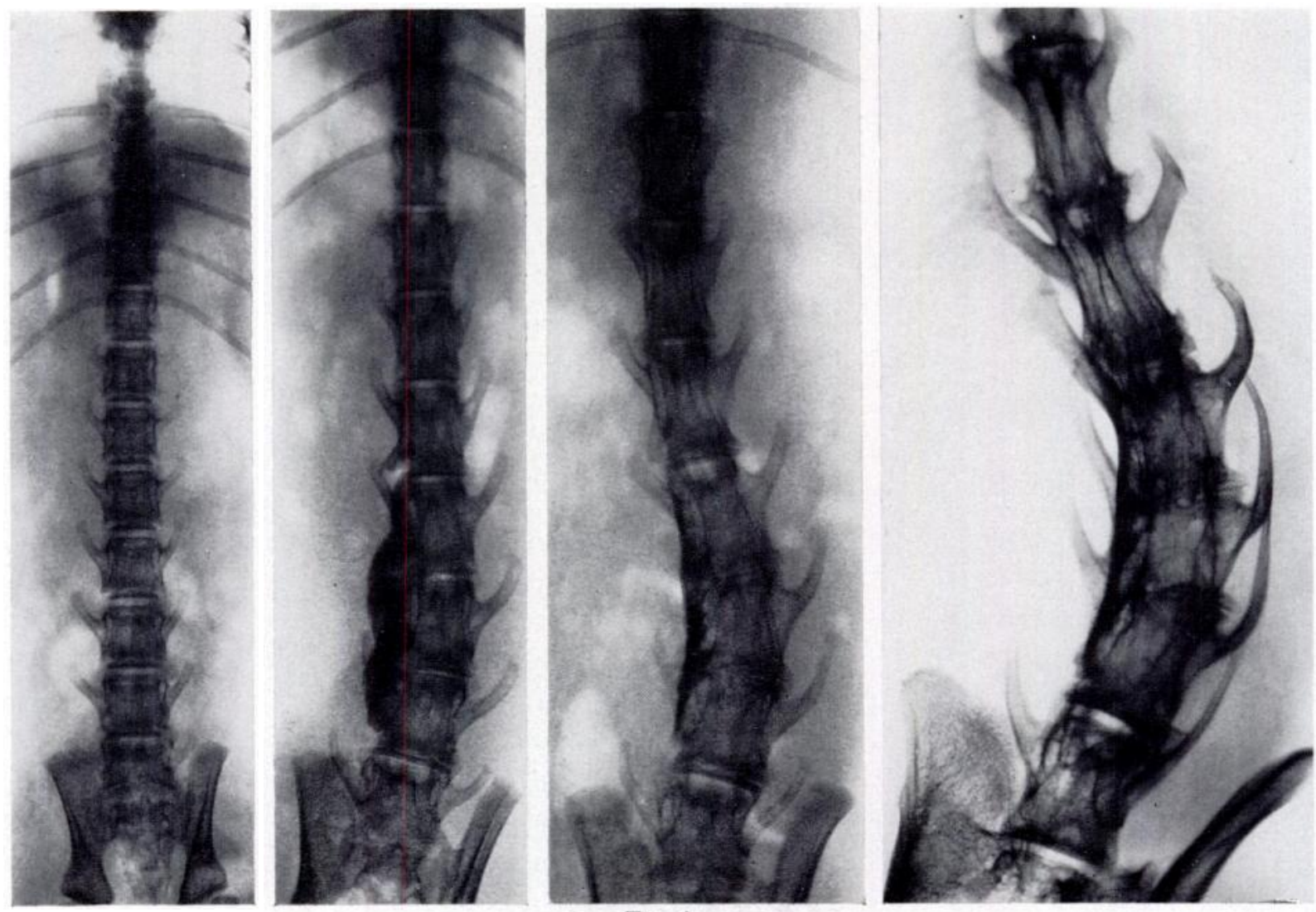

FIG. 1

Rabbit No. 35. Radiographs showing progressive bone formation after transplantation of periosteum from the fourth to the sixth lumbar vertebrae, immediately after the operation and one, three and twelve months later.

Of the eight spaces grafted bilaterally and posteriorly, fusion occurred in all eight - three thoracic, one thoracolumbar and four lumbar (see column 7).

Pseudarthrosis developed in ten interspaces involving nine rabbits (see column 8). The possible reasons were the use of tissue adhesive (four), a homograft (one), twin transplants (four) and muscle interposition (one) (see Remarks).

In nineteen rabbits with postero-lateral grafting, unilateral of course, a lateral curvature developed in every case (see columns 9 and 10).

In twelve rabbits posterior fusion occurred and all developed a lordosis except one in which a homograft had been transplanted (see columns 11 and 12). This one failure to develop a lordosis may have been due to delay in the onset of fusion. stage, and defects like pseudarthrosis were seen at the level of the interspace (Fig. 2). After five to seven weeks such defects usually could no longer be seen in the fusion mass (Fig. 2), which became more dense and more uniform with time and stayed so.

When the transplant had been placed posterolaterally across the transverse processes on one side, a progressive lateral curvature was observed from the fourth week onwards (Figs. 1 and 3). This curvature was more prominent in the lumbar and thoraco-lumbar spine, but a slight curvature was also found constantly in the thoracic spine when fusion had occurred.

In younger rabbits a disturbance of growth could be observed within four wecks of the operation. Narrowing and wedging of the intervertebral space was followed by retardation of growth and lateral wedging of the vertebrae 


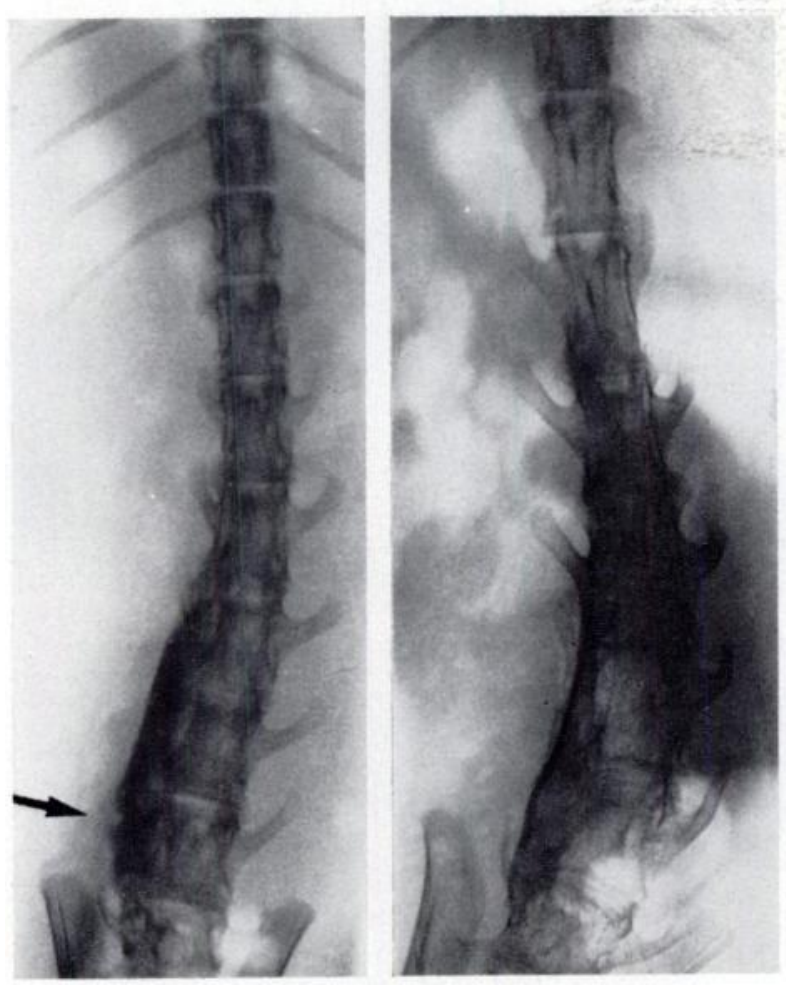

FIG. 2

Rabbit No. 36. Radiographs showing a defect like a pseudarthrosis in the region of the transplant three weeks after operation, and the same area at three months showing solid bony fusion from the fourth to the seventh lumbar vertebrae.

(Figs. 1 and 3). In both unilateral and bilateral posterior fusions, lordosis with antero-posterior wedging of the local vertebrae developed in the fourth week (Fig. 4).

\section{Macroscopic observations}

These confirmed the radiographic findings (Fig. 5). The convex side of a curve or lordosis also showed a tendency to spontaneous fusion. Progressive narrowing and deformity of the articular facets were observed.

\section{Histological examination}

At the time of operation the transplanted periosteum appeared to be a layer of fibrous tissue. Proliferation of chondrogenetic cells started from the deep or bone side of the transplant; after two weeks they had differentiated into cartilage cells, forming a fusion mass like callus. This began to calcify and in two months was transformed into solid bone of normal structure, well vascularised and with a fully developed Haversian system. Even bone marrow was present (Fig. 6). The last sites to ossify were the interspace levels.

\section{DISCUSSION}

The effect on growth of early fusion of the spine is a very important problem and many clinical questions have not yet been solved. Opinions vary widely as to the nature and significance of the changes that may occur in the human spine after posterior fusion in children. Some claim that early fusion may cause a significant disturbance
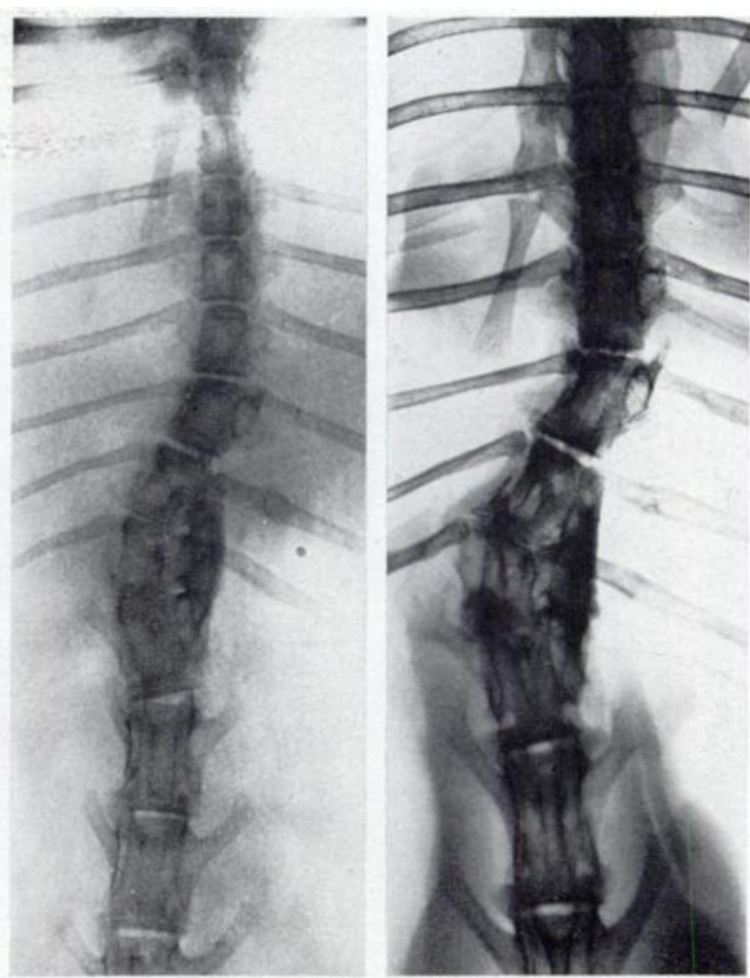

FIG. 3

Rabbit No. 19. Radiographs taken six weeks and three months after operation showing bone formation and progressive lateral curvature in the thoraco-lumbar region.

of growth whereas others do not believe this to be true. In a number of studies of spines that appeared to be soundly fused continued growth in length has been described (Risser 1956; Cleveland, Bosworth, Fielding and Smyrnis 1957, 1958), but many researchers, like

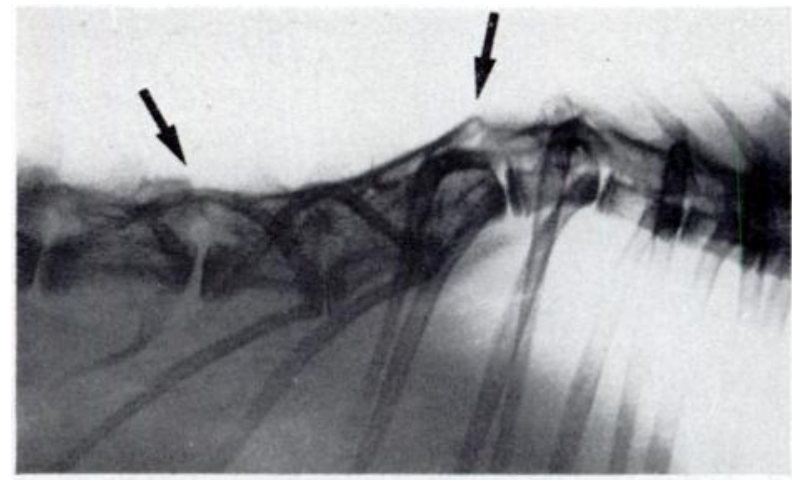

Fig. 4

Rabbit No. 12. Posterior bilateral paraspinous fusion in the lower thoracic region and the resulting lordosis five months after the operation.

Ponseti and Friedman (1950), Hallock, Francis and Jones (1957), Scheier (1969) and Winter (1971), disagree. Johnson and Southwick (1960h) assume that pseudarthroses or stress fractures must have occurred in cases where growth of the fused area was seen. A possible way to find out the effects of spine fusion in young children would be a controlled study in young animals. 

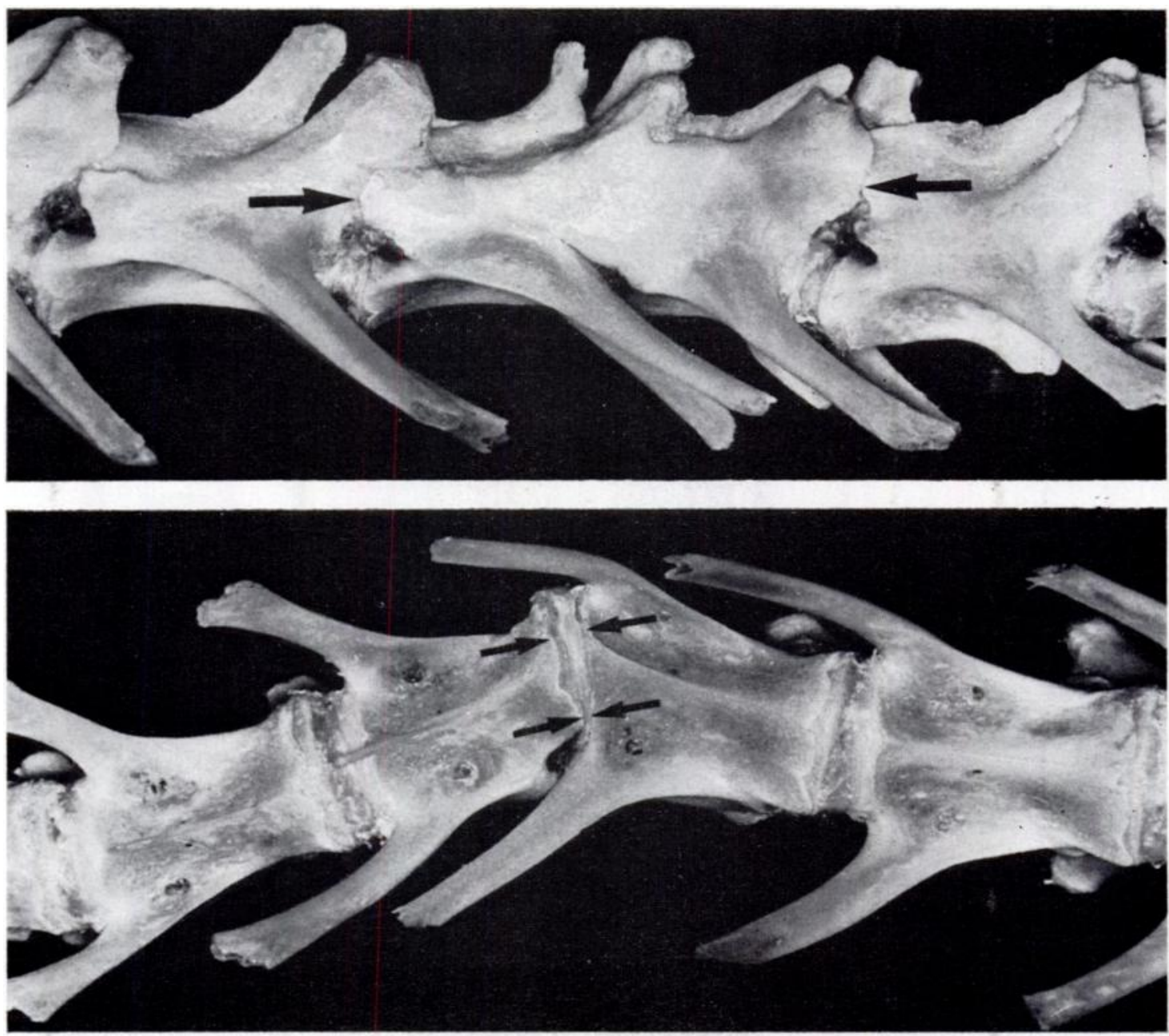

FIG. 5

Rabbit No. 31. Lateral and antero-posterior photographs of two lumbar vertebrae three and a half months after operation. The lateral view (above) shows a bone bridge across the fusion area between the arrows. The ventral view (below) shows growth disturbances with narrowing and wedging of both the vertebrae and the disc, and a lateral curvature of the spine.

In our experiments we operated on different levels of thoracic and lumbar spine and no immobilisation was used. The fact that we obtained a high percentage of

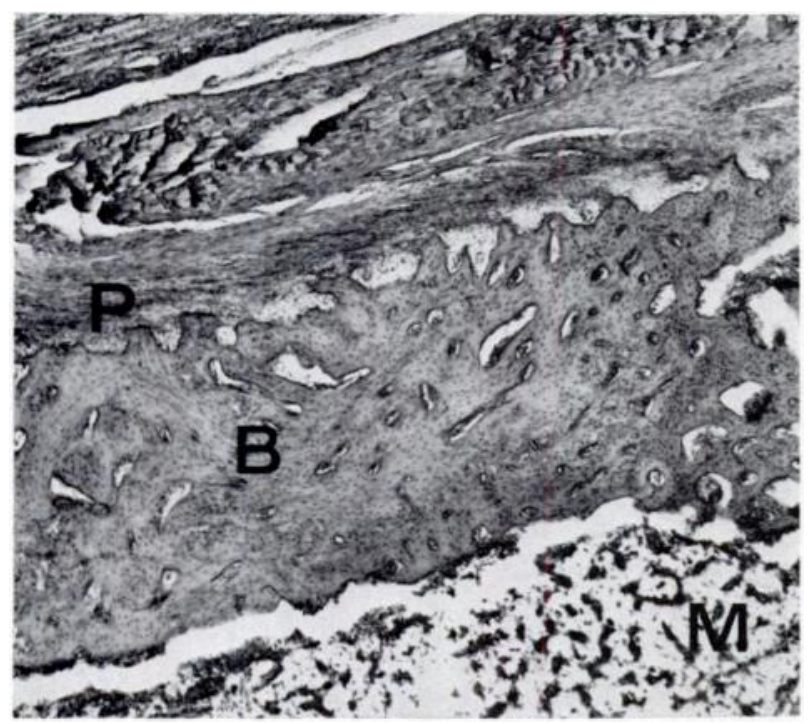

FIG. 6 fusion may be due to the properties of the periosteum. Unlike a bone graft a periosteal graft does not have a resorptive stage; instead, after a short cartilaginous stage, it usually causes sound bony fusion of the vertebrae. This may also explain the growth disturbances of the spine recorded in our study; these have not always been seen after grafting with bone, possibly due to pseudarthroses in the region of the supposed fusion.

A most important question is: can a fused spine grow? The findings of this study show that in young rabbits spinal fusion with free periosteal grafts disturbs local growth. The bone bridge between the spinal arches possibly prevents normal epiphysial growth of the related vertebrae, causing premature closure and the onset of scoliosis.

Another question is whether or not early fusion of a growing scoliotic spine can prevent the curve from worsening, and if so, to what degree. There are many

Figure 6-Rabbit No. 16. A histological section of the fusion area. $\mathbf{B}=$ Bone formed by the transplant between two vertebrae, structurally like normal rabbit bone with blood vessels and a fully developed Haversian system. $M=$ Bone marrow in the transplant. $\mathbf{P}=$ Periosteal fibrous tissue layer. (Haematoxylin and eosin, $\times 75$.) 
variable factors such as age, the time lapse before fusion is sound, the level and the length of the fusion. The growth disturbance observed in the present experiments offers a possibility for the dynamic correction of a scoliosis in a child if the fusion is performed on the convex side. In a study yet to be reported we have used spinal fusion with free periosteal grafts to determine the effect of spinal fusion on experimental scoliosis.

Findings in growing rabbits, however, are not necessarily applicable to man. Man is a biped and the rabbit is a quadruped, with attendant differences in spinal mechanics.

\section{REFERENCES}

Albee, F. H. (1913) An experimental study of bone growth and the spinal bone transplant. Journal of the American Medical Association, 60, $1044-1049$.

Bisgard, J. D., and Musselman, M. M. (1940) Scoliosis. Its experimental production and growth correction; growth and fusion of vertebral bodies. Surgery, Gynecology and Obstetrics, 70, 1029-1036.

Cleveland, M., Bosworth, D. M., Fielding, J. W., and Smyrnis, P. (1957) Fusion of the spine for tuberculosis in children. Journal of Bone and Joint Surgery, 39-A, 701.

Cleveland, M., Bosworth, D. M., Fielding, J. W., and Smyrnis, P. (1958) Fusion of the spine for tuberculosis in children. Journal of Bone and Joint Surgery, 40-A, 91-106.

Coleman, S. S. (1968) The effect of posterior spine fusion on vertebral growth in dogs. Journal of Bone and Joint Surgery, 50-A, 879-896.

Haas, S. L. (1940) Influence of fusion of the spine on the growth of the vertebrae. Archives of Surgery, 41, 607-624.

Hallock, H., Francis, K. C., and Jones, J. B. (1957) Spine fusion in young children. Journal of Bone and Joint Surgery, 39-A, 481-491.

Hurley, L. A., Stinchfield, F. E., Basset, C. A. L., and Lyon, W. H. (1959) The role of soft tissues in osteogenesis. Journal of Bone and Joint Surgery, 41-A, 1243-1254.

Johnson, J. T. H., and Southwick, W. O. (1960a) Growth following transepiphyseal bone grafts. Journal of Bone and Joint Surgery, 42-A, 1381-1395.

Johnson, J. T. H., and Southwick, W. O. (1960b) Bone growth after spine fusion. Journal of Bone and Joint Surgery, 42-A, $1396-1412$.

Kornew, P. G. (1929) Transplantation und Knochenwachstum. Experimentelle Untersuchung. Archiv für Klinische Chirurgie, $154,499-564$.

Odelberg-Johnson, G. (1939) On defects and pseudarthroses of the bony bridge following paraspinal bone transplantation in growing rabbits. Acta orthopaedica Scandinavica, 10, 160-219.

Ponseti, I. V., and Friedman, B. (1950) Changes in the scoliotic spine after fusion. Journal of Bone and Joint Surgery, 32-A, 751-766.

Risser, J. C. (1956) Vertebral growth and spine fusion. Journal of Bone and Joint Surgery, 38-A, 1386.

Ritsilk, V., and Alhopuro, S. (1972) Experimental studies on the repair of bone defects and tracheal cartilage defect with free periosteum. Scandinavian Journal of Clinical and Laboratory Investigation, 29, Supplement 122, 51.

Ritsilä, V., and Alhopuro, S. (1973) Reconstruction of experimental tracheal cartilage defects with free periosteum. Scandinavian Journal of Plastic and Reconstructive Surgery, 7, 116-119.

Ritsila, V., Alhopuro, S., Gylling, U., and Rintala, A. (1972) The use of free periosteum for bone formation in congenital clefts of the maxilla. Scandinavian Journal of Plastic and Reconstructive Surgery, 6, 57-60.

Ritsiliz, V., Alhopuro, S., and Rintala, A. (1972) Bone formation with free periosteum. Scandinavian Journal of Plastic and Reconstructive Surgery, 6, 51-56.

Scheier, H. J. (1969) Spondylodese und Wachstum. Zeitschrift für Orthopaedie und ihre Grenzgebiete, 106, $430-437$.

Veliskakis, K., and Levine, D. B. (1966) Effects of posterior spine fusion on vertebral growth in dogs. Journal of Bone and Joint Surgery, 48-A, 1367-1376.

Winter, R. B. (1971) The effects of early fusion on spine growth. In Scoliosis and Growth. Proceedings of a Third Symposium held at the Institute of Diseases of the Chest, Brompton Hospital, London, on 13th November 1970, pp. 98-104. Edited by P. A. Zorab. Edinburgh and London: Churchill Livingstone. 